\title{
The anti-inflammatory and antioxidant effects of thymoquinone on ceruleine-induced acute pancreatitis in rats
}

\author{
Dur $\mathrm{A}^{1}$, Kose $\mathrm{H}^{2}$, Kocyigit $\mathrm{A}^{3}$, Kocaman $\mathrm{O}^{4}$, Ismayilova $\mathrm{M}^{5}$, Sonmez $\mathrm{FC}^{6}$ \\ Department of Emergency Medicine, Bezmialem Vakif University Faculty of Medicine, Istanbul, Turkey. \\ dralidur@hotmail.com
}

\begin{abstract}
INTRODUCTION: The aim of this study is to investigate the potential antioxidant and anti-inflammatory effects of thymoquinone (TQ) on ceruleine-induced acute pancreatitis.

MATERIAL AND METHODS: A total of 14 male Wistar albino rats were divided into 2 groups as follows: (1) normal saline-treated group and (2) thymoquinone- treated groups. For achieving acute pancreatitis, intraperitoneal (IP) cerulein, a stable cholecystokinin (CCK) analogue, was applied in a $50 \mathrm{mcg} / \mathrm{kg}$ dose 2 times in onehour interval in total. One hour after last ceruleine injection, IP $2 \mathrm{ml} / \mathrm{kg}$ isotonic saline solution was applied to the saline group and IP $5 \mathrm{mg} / \mathrm{kg}$ TQ was applied. The rats were sacrificed by decapitation $12 \mathrm{~h}$ after the last

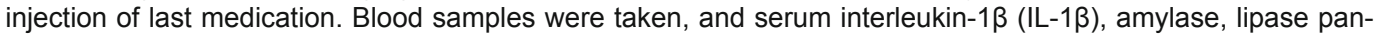
creatic, total antioxidant capacity (TAC), total oxidant status (TOS), and pancreatic Schoenberg scores were determined. Oxidative stress index (OSI) was calculated for each group. Results are given as mean \pm SD. A value of $p<0.05$ was accepted as statistically significant. SPSS for Windows v15.0 was used for statistical analyses. RESULTS: The increased serum amylase, lipase levels and histopathological scoring of pancreatic tissue showed that acute pancreatitis was present in both groups. Furthermore, serum IL-1 $\beta$ level was significantly reduced in TQ-administered group $(p<0.05)$. Although serum TAC level was high and TOS level was low, those changes were not statistically significant. Nevertheless, OSI index, which was driven from TOS/TAC, was significantly low in TQ groups $(p<0.05)$. Although TQ partially ameliorated the acute pancreatitis in terms of histopathological evaluations, the main effect of it was brought about by reducing the hemorrhage in acute pancreatitis $(p<0.05)$. CONCLUSION: In this study, it was shown that TQ can reduce the inflammation and has a positive effect on the oxidative status of organism in inflammatory cases such as acute pancreatitis. This is consistent with partial amelioration of acute pancreatitis in rats given TQ (Tab. 2, Fig. 4, Ref. 31). Text in PDF www.elis.sk. KEY WORDS: acute pancreatitis, thymoquinone, inflammation, rat.
\end{abstract}

\section{Introduction}

Acute pancreatitis (AP) is a sudden inflammatory disease of the pancreas that frequently involves peri-pancreatic tissues and remote organ systems (1). The progression of the disease cannot be anticipated truly, however severe necrotic cases may cause increased morbidity and mortality (2). Early activation of pancreatic enzymes and pancreatic acinar cell injury cause acute pancreatitis. Acinar cell injury activates the immune system which results in the increase in inflammatory cells such as neutrophils and mac-

${ }^{1}$ Department of Emergency Medicine, Bezmialem Vakif University Faculty of Medicine, Istanbul, Turkey, ${ }^{2}$ Department of Biophysics, Bezmialem Vakif University Faculty of Medicine, Istanbul, Turkey, ${ }^{3}$ Department of Biochemistry, Bezmialem Vakif University Faculty of Medicine, Istanbul, Turkey, ${ }^{4}$ Department of Gastroenterology, Bezmialem Vakif University, Faculty of Medicine, Istanbul, Turkey, ${ }^{5}$ Department of Internal Medicine, Biruni University Faculty of Medicine, Istanbul, Turkey, and ${ }^{6}$ Department of Pathology, Bezmialem Vakif University, Faculty of Medicine, Istanbul, Turkey

Address for correspondence: Ali Dur, MD, Bezmialem Vakif University, Faculty of Medicine, Department of Emergency Mmedicine, Vatan street, Fatih, Istanbul, Turkey. rophages, and proinflammatory cytokines such as interleukin-1, interleukin-6, IL-1 $\beta$ and TNF-a releases. These cytokines may increase the damage of acinar cells and result in necrosis of pancreas $(3,4)$. Although numerous trials have studied the mechanism of AP pathogenesis, the detailed mechanism remains unclear (5). In experimental animal models, an administration of supramaximal doses of the cholecystokinin analog secretagogue cerulein induces acute pancreatitis characterized by structural changes in pancreas, such as edema and massive disruption of acinar cells, and increases laboratory parameters such as serum amylase and lipase (6). Thymoquinone (TQ), an aromatic ketone, is the major active compound derived from the seeds of Nigella sativa, known as black cumin in English. Nigella sativa oil and itself are widely used in the treatment of many common diseases in traditional medicine. In last five decades, many active ingredients have been extracted from Nigella sativa seeds and their pharmacological effects have been studied (7). In recent years, many studies have revealed the benefits of extraction used in a spectrum from infectious diseases to cardiovascular system diseases $(8,9)$. The studies relevant to pharmacological properties of TQ have suggested that antioxidant and antiinflammatory effects can be effective but research on the subject has not been sufficiently illuminated (10). In this study, oxidative 
and anti-inflammatory activities of TQ were investigated under inflammatory condition by intraperitoneal administration of TQ.

\section{Materials and methods}

The experimental protocol was approved by the Local Experimental Animal Care Committee at the Bezmialem Vakif University. In this study were 14 adult male Wistar Albino rats, weighing 200-250 g were used. The study was performed at Bezmialem Vakif University Experimental animal research center. The animals were randomized into 2 groups: Saline-treated group (STG) and Thymoquinone-treated groups (TTG), in equal numbers. Animals were fed with standard laboratory chow, and allowed water ad libitum. They were housed under a 12 -h light/12-h dark cycle at $21^{\circ} \mathrm{C}$.

\section{Experimental plan}

Experimental acute pancreatitis was performed in each group by injecting $50 \mu \mathrm{g} / \mathrm{kg}$ cerulein (Sigma Chemical Co., St. Louis, MO) intraperitoneally 2 times in $1-\mathrm{h}$ interval. The rats in the STG were given intraperitoneal (IP) injections of $2 \mathrm{ml}$ saline 1 hour after the last cerulein dose. The rats in the TTG were given IP injection of $5 \mathrm{mg} / \mathrm{kg}$ TQ (Sigma Chemical Co., St. Louis, MO) 1 hour after last cerulein dose. Paracetamol (Atabay Drug Factory) at a dose of $250 \mathrm{mg} / \mathrm{kg}$ was applied to all groups every 6 hours (totally two times) for pain palliation.

Two of the rats which died in STG group during follow-up were excluded from the study. Rats in each group were sacrificed by taking blood sample from heart under $20 \mathrm{mg} / \mathrm{kg}$ ketamine hydrochloride (Ketalar, Parke-Davis, USA) anesthesia. At the end of the experiment, under sterile condition, laparotomy and midline incision were applied to all of the rats. Blood samples were obtained by direct intracardiac puncture. Samples were immediately transferred into a heparinized tube, stored at $2-40{ }^{\circ} \mathrm{C}$ in the dark to prevent further DNA damage and processed within 2 hours. A volume of 1 $\mathrm{ml}$ of blood was removed to separate damaged mononuclear leukocyte DNA and remaining blood was centrifuged at $3000 \mathrm{x}$ g for 10 minutes. Plasma samples were stored at $-80^{\circ} \mathrm{C}$ until biochemical analysis. Mononuclear leukocytes were isolated by centrifugation on Histpaque 1077 (Sigma Aldrich). A volume of $1 \mathrm{ml}$ of heparinized blood was carefully layered over $1 \mathrm{ml}$ of Histopaque and centrifuged for $35 \mathrm{~min}$. at $500 \mathrm{xg}$ at $25^{\circ} \mathrm{C}$. Each interface band containing mononuclear leukocytes was washed with phosphatebuffered saline (PBS) and collected by 15 -min centrifugation at 400 $\mathrm{x}$ g. PBS. The resulting pellets were re-suspended with PBS. Membrane integrity was assessed using trypan-blue exclusion assay.

The same researcher made all dissections, and all pancreatic tissues were fixed in formaldehyde for histological examination. The intensity of pancreatitis was graded by serum amylase, lipase, IL-1 $\beta$ and histopathological grading of pancreas.

\section{Biochemical analysis}

Serum amylase and lipase levels were measured with Cobas Integra 400 plus (Roche Diagnostics, Rotkreuz, Switzerland) using commercial kits (Roche Diagnostic). IL-1 $\beta$ were measured by ELISA method using commercial kit (eBioscience).

\section{Measurement of total antioxidant capacity}

Total antioxidant capacity (TAC) of supernatant fractions was determined using a novel automated measurement method developed by Erel (11). Hydroxyl radicals, the most potent biological radicals, are produced by this method. In the assay, the ferrous ion solution present in Reagent 1 is mixed with hydrogen peroxide, which is present in Reagent 2 . The subsequently produced radicals such as brown-colored dianisidinyl radical cations produced by the hydroxyl radicals, are also potent radicals. Using this method, the antioxidative effect of the sample was measured against the potent free-radical reactions initiated by the produced hydroxyl radicals. The assay has excellent precision, with values lower than $3 \%$. The results are expressed as nmolTrolox Equiv./ /mg protein.

\section{Measurement of total oxidant status}

Total oxidant status (TOS) of supernatant fractions was determined using a novel automated measurement method developed by Erel (12). Oxidants present in the sample oxidize the ferrous ion-o-dianisidine complex to ferric ion. The oxidation reaction is enhanced by glycerol molecules, which are abundant in the reaction medium. The ferric ion produces a complex colored with xylenol orange in an acidic medium. The color intensity, which can be measured spectrophotometrically, is related to the total amount of oxidant molecules present in the sample. The assay was calibrated with hydrogen peroxide, and the results are expressed in terms of $\mathrm{nmol} \mathrm{H}_{2} \mathrm{O}_{2}$ Equiv/mg protein.

\section{Oxidative stress index}

The percentage ratio of TOS level to TAC level was defined as OSI. OSI values were calculated according to the following formula (13): OSI (arbitrary unit) $=\mathrm{TOS}\left(\mathrm{nmol} \mathrm{H}_{2} \mathrm{O}_{2}\right.$ Equiv/mg protein)/TAC (nmolTroloxEquiv/mg protein) / 10.

\section{Mononuclear leukocyte DNA damage determination by alkaline comet assay}

The endogenous DNA damage in mononuclear leukocyte was analyzed by alkaline comet assay according to Singh et al. (14) with minor modification. Thus, mononuclear leukocytes were embedded in $0.7 \%$ low-melting-point agarose (LMA) (Sigma) in PBS at $37^{\circ} \mathrm{C}$ at a final concentration of $10^{4}$ cells $/ \mathrm{mL}$. Then, $80 \mu \mathrm{L}$ of this cellular suspension was spread onto roughened slides that had previously been coated with $1.0 \%$ hot $\left(60^{\circ} \mathrm{C}\right)$ normal melting point agarose (NMA), covered with a cover slip at $4{ }^{\circ} \mathrm{C}$ for at least 5 min to allow the agarose to solidify, and transferred to a humidified box after removal of cover slips. Slides were allowed again to solidify for $5 \mathrm{~min}$ at $4{ }^{\circ} \mathrm{C}$ in a moist box. After removing cover slips, the slides were submersed in freshly prepared cold (4 $\left.{ }^{\circ} \mathrm{C}\right)$ lysing solution $(2.5 \mathrm{M} \mathrm{NaCl}, 100 \mathrm{mM}$ EDTA-2Na; $10 \mathrm{mM}$ Tris$\mathrm{HCl}, \mathrm{pH} 10-10.5 ; 1 \%$ Triton X-100 and $10 \%$ DMSO added just before use) for at least $1 \mathrm{~h}$. Slides were then immersed in freshly prepared alkaline electrophoresis buffer $(0.3 \mathrm{~mol} / \mathrm{L} \mathrm{NaOH}$ and 1 $\mathrm{mmol} / \mathrm{L} \mathrm{Na} 2 \mathrm{ETDA}, \mathrm{pH}>13$ ) at $4^{\circ} \mathrm{C}$ for unwinding (40 min) and then electrophoresed (25 V/300 mA, $25 \mathrm{~min})$. All of the above steps were conducted under red light or away from direct light in 
614-618
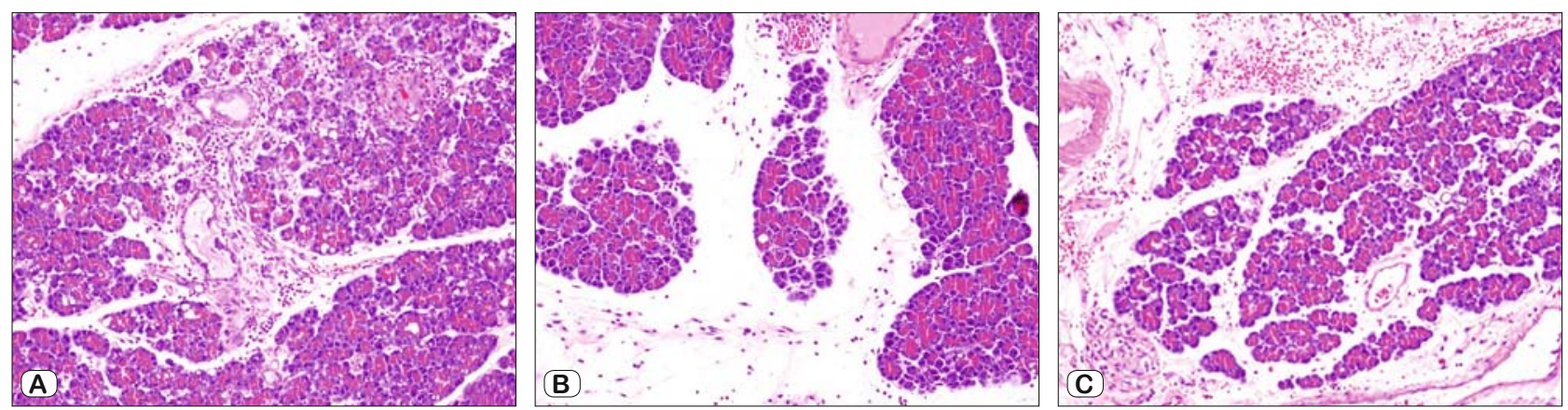

Fig. 1. Photomicrographs (A) Acinar cell vacuolization, edema and inflammatory cell infiltrate, H-E, X100 (B) Edema, H-E, X100 (C) Acinar cell degeneration, edema and hemorrhage, H-E, X100.

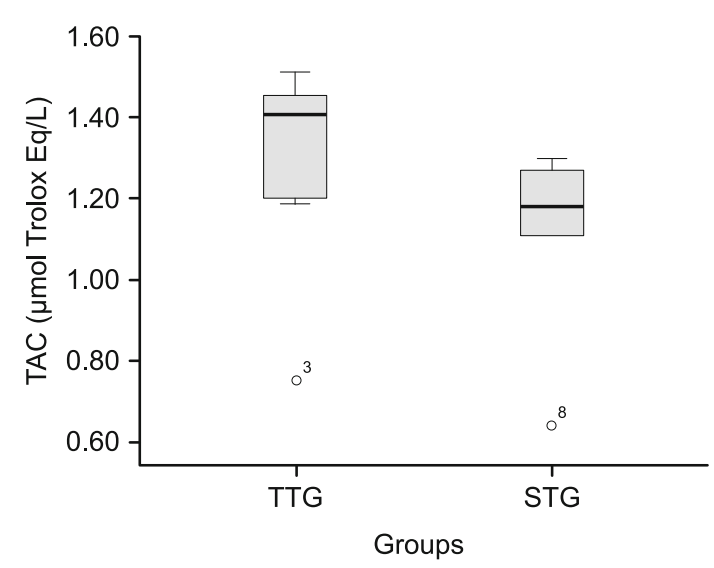

Fig. 2. TAC levels for TTG and STG groups. * $p>0.05$ compared with TTG and STG groups.

order to prevent additional DNA damage. After electrophoresis, the slides were stained with ethidium bromide $(2 / \mathrm{mL}$ in distilled $\mathrm{H}_{2} \mathrm{O} ; 70 \mathrm{~L} /$ slide), covered with a cover slip and analyzed using a fluorescence microscope (Nikon). Images of 100 randomly selected cells (50 cells from each of two replicate slides) were analyzed visually from each subject, as described elsewhere $(15,16)$. Each image was classified according to the intensity of the fluorescence in the comet tail and was given a value of either of $0-3$ or 4 (from undamaged Class 0 to maximally damaged Class 4) (Fig. 1), so that the total scores of a slide could be between 0 and 400 arbitrary units. All procedures were completed by the same biochemistry staff, and DNA damage was detected by a single observer who was not aware of subject's diagnosis.

\section{Histopathologic examinations of pancreatic tissues}

Formalin-fixed, paraffin-embedded tissues were cut into 5$-\mu \mathrm{m}$ sections and stained using the hematoxylin-eosin (H-E) stain. Each specimen was examined and scored according to Schmidt's standards. Acinar cell degeneration, inflammatory cell infiltration, edema and hemorrhage were evaluated and 0-3 points were given for each criteria so the maximum score was calculated as 12 for tissue (Fig. 1). Blind evaluation was performed for histopathologic examination.

\section{Statistical analysis}

Statistical evaluation was done with SPSS program operating under Windows. The Mann-Whitney U-test was used to compare parameters between the 2 groups. Values of $p<0.05$ were taken as significant. The results were defined as mean \pm standard deviation (SD). Spearman correlation coefficient was used to evaluate the relationship between variables.

\section{Results}

During the studies, 2 rats died in STG. Therefore, the results of 5 rats in STG and 7 rats in TTG were obtained. No significant differences were found between serum amylase and lipase results of the 2 groups ( $p>0.05$ ) (Tab. 1). In TTG groups, serum IL-1 $\beta$ levels were significantly decreased compared to STG $(p<0.05)$ (Tab. 1). Although TAC activity in TTG group was greater than STG group and TOS activity in TTG group was smaller than STG group, no statistical significance was observed between groups. OSI activity in blood samples was statistically lower in TTG than in STG. The results are summarized in Figures 2, 3, and 4. This study showed that TQ has partial healing effects on pancreatitis but a significant reduction was observed in cases of hemorrhage complication of pancreatitis $(\mathrm{p}<0.05)$ (Tab. 2).

\section{Discussion}

In this study, the effect of IP TQ application on the model of cerulein-induced acute pancreatitis was investigated in terms of

Tab. 1. DNA damage values, oxidative stress parameters and biochemical markers in the blood (mean $\pm \mathrm{SE}$ ).

\begin{tabular}{lccc}
\hline Parameters & $\begin{array}{c}\text { TTG } \\
(\mathrm{n}=7)\end{array}$ & $\begin{array}{c}\text { STG } \\
(\mathrm{n}=5)\end{array}$ & $\mathrm{p}$ \\
\hline TOS $\left(\mu \mathrm{mol} \mathrm{H}_{2} \mathrm{O}_{2}\right.$ equiv./L) & $8.65 \pm 3.28$ & $11.95 \pm 2.97$ & 0.062 \\
TAC $(\mathrm{mmol}$ Trolox equiv./L) & $1.29 \pm 0.26$ & $1.10 \pm 0.26$ & 0.123 \\
OSI $(\mathrm{AU})$ & $0.65 \pm 0.23$ & $1.22 \pm 0.77$ & 0.042 \\
DNA damage $(\mathrm{AU})$ & $19.32 \pm 12.11$ & $17.85 \pm 3.63$ & 0.935 \\
Amylase & $3122 \pm 1204$ & $2951 \pm 1135$ & 0.907 \\
Lipase & $133.79 \pm 134.43$ & $128.16 \pm 110.83$ & 0.844 \\
IL-1 $\beta$ & $52.91 \pm 21.85$ & $103.95 \pm 50.84$ & 0.042 \\
\hline
\end{tabular}

Values are mean \pm S.D. TTG - Thymoquinone Treated Group; STG - Saline Treated Group; AU - arbitrary units; TAC - Total Antioxidant Capacity; TOS - Total Oxidant Status; OSI - Oxidative Stress Index. Significance was defined as $\mathrm{p}<0.05$. 


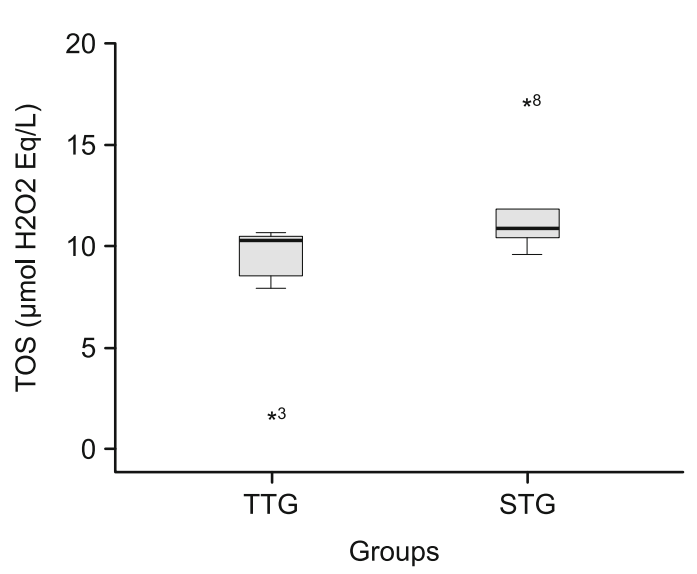

Fig. 3. TOS levels for TTG and STG groups. * $p>0.05$ compared with TTG and STG groups.

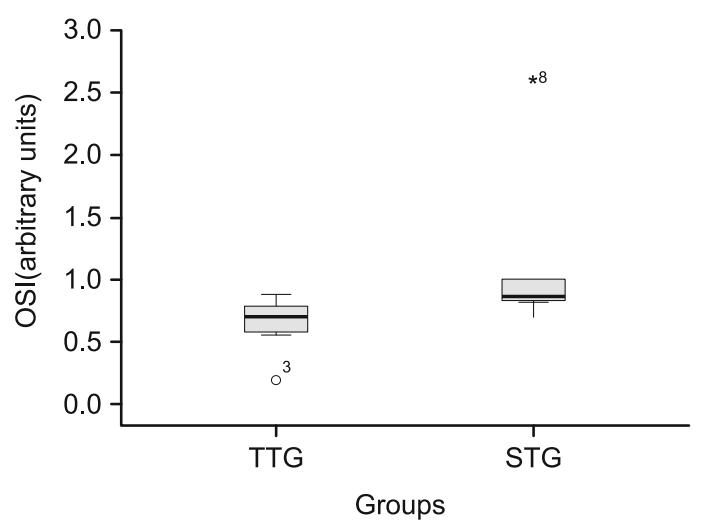

Fig. 4. OSI levels for TTG and STG groups. * $p<0.05$ compared with TTG and STG groups.

anti-inflammatory, antioxidant and protective effect on DNA damage. In a limited number of previous studies, long-term oral administration of TQ may be effective in diseases where inflammation and reactive oxygen species (ROS) are a prominent factor, but the pathophysiology of this effect is unclear $(17,18)$. Although several studies show that it is not clearly elucidated in the pathogenesis of acute pancreatitis, inflammation and ROS have an important role in the pathogenesis $(19,20)$. The literature search shows that there is no study related to TQ effect on inflammation, oxidative status and cytoprotective effect in acute pancreatitis model.

Cerulein has cholecystokinin (CCK)-like structure, interacts with pancreatic acinar cells and causes maximum pancreatic secre-

Tab. 2. Histological scores of pancreatic injury (mean \pm SE).

\begin{tabular}{lccc}
\hline Parameters & $\begin{array}{c}\text { TTG } \\
(\mathrm{n}=7)\end{array}$ & $\begin{array}{c}\text { STG } \\
(\mathrm{n}=5)\end{array}$ & $\mathrm{p}$ \\
\hline Acinar cell degeneration & $2 \pm 0$ & $2.20 \pm 0.45$ & 0.237 \\
Inflammation & $1.71 \pm 0.95$ & $1.80 \pm 0.84$ & 0.792 \\
Edema & $2.14 \pm 0.38$ & $2.40 \pm 0.55$ & 0.332 \\
Hemorrhage & $0.29 \pm 0.76$ & $1 \pm 0$ & 0.024 \\
Total score & $6.14 \pm 1.46$ & $7.40 \pm 1.34$ & 0.133 \\
\hline Values are mean + S.D. Significance was defined as $\mathrm{p}<0.05$ & &
\end{tabular}

Values are mean \pm S.D. Significance was defined as $p<0.05$. tion of inflammatory markers such as amylase, lipase and IL-1 $\beta$ $(21,22)$. The death of acinar cells, edema formation, cytoplasmic vacuolization, and infiltration of inflammatory cells into the pancreas simulate the characteristics of human pancreatitis. The suggested mechanism of cerulein is to include production of large amounts of ROS, activation of oxidant-sensitive transcription factor nuclear factor-kb (nf-kb) and induction of cytokine expression in pancreas $(23,24)$.

IL-1 $\beta$ is one of the most important acute phase mediators and it plays an important role in the development of AP. In several studies, it was shown that inhibition of IL- $1 \beta$ production reduced AP severity and the reduced pro-inflammatory cytokines have been proposed to play the key role in AP healing $(25,26)$. In our study, cerulein infusion resulted in acute pancreatitis model that was proved by high levels of amylase and lipase and histopathologic findings in rats. When the histopathologic results were analyzed, it was seen that TQ treatment reduced the severity of pancreatitis compared to that in normal saline group. This effect was limited and significant with the reduction in hemorrhagic complications of the pancreatitis. Taking the biochemical parameters into consideration, it was found that $5 \mathrm{mg} / \mathrm{kg}$ dose of TQ has no activity on the level of amylase and lipase. However, the main effect of TQ was on IL-1 $\beta$ level. The level of IL-1 $\beta$ in TTG group was significantly reduced. In previous studies, it has been reported that the anti-inflammatory effect of TQ was related to the blockage of the synthesis of leukotrienes and thus to the prevention of tissue inflammation and oxidative damage $(27,28)$. In our study, TQ showed its anti-inflammatory effect by strong suppression of IL-1 $\beta$ synthesis. It may be hypothesized that TQ treatment generates anti-inflammatory activity by reducing the level of IL-1 $\beta$. The reduction in the level of IL-1 $\beta$ may reduce the severity and complications of acute pancreatitis histopathologically.

The previous studies in the treatment of rheumatoid arthritis and in the present rat model of acute pancreatitis, effective antiinflammatory property of TQ offers its promise in the treatment of inflammatory disorders $(14,15,29)$. TQ with its antioxidant defense mechanisms through the effects of lipid peroxidation reduces antioxidant markers of MDA and NO levels and leads to an increase in the levels of SOD, CAT and GPx. In addition to these features, studies reported antioxidant effects of TQ on infectious cases in prostate gland and on atherosclerosis in acute coronary syndromes $(30,31,16)$. To explore the antioxidant ability of TQ in these studies, they evaluated oxidant (NO and MDA) and antioxidant (SOD, CAT, and GPX) activity, which is directly related to the reaction of the inflamed tissue as it is released from infiltrated cells at the site of infection. In this work, we used EREL method to evaluate the activity of TQ on inflammatory diseases; comet assay was studied to observe the effectiveness of TAC-TOS and TQ on DNA damage. In our study, TAC levels were increased by the use of TQ but the results were not statistically significant. However, almost a significant decrease was observed after the TQ treatment at TOS levels. The evaluation of OSI which can provide more comprehensive and clear information about the oxidative status in the body, revealed that the reduction in the value of OSI in TQ group was statistically significant. At the given dose of TQ, 
614-618

there was no difference in the prevention of DNA damage, NST group and cytoprotective activity.

Our study had limitations related to the number of rats recruited in the study. The results are based on a small number of rats which jeopardized the power of the study. Furthermore, we used a limited number of inflammatory markers and cytokine profile for the cost effectiveness of the study.

In conclusion, TQ treatment in the acute pancreatitis model has no effect on cell protection. Although TQ has positive antioxidant effects on living organisms, the absence of this effect at a cell level remains to be studied in further double-blinded, randomized, placebo-controlled clinical trials with larger sample sizes.

\section{References}

1. Bhatia M, Wong FL, Cao Y et al. Pathophysiology of acute pancreatitis. Pancreatology 2005; 5: 132-144.

2. Pandol SJ, Saluja AK, Imrie CW, Banks PA. Acute pancreatitis: bench to the bedside. Gastroenterology 132: 1127-1151.

3. Yu X, Li YG, He XW, Li XR, Din BN, Gan Y, Xu M. Hyperbaric oxygen reduces inflammatory response in acute pancreatitis by inhibiting NF-kappa B activation. Eur Surg Res 42: 130-135.

4. Zhang XP, Jiang J, Yu YP, Cheng QH, Chen B. Effect of Danshen on apoptosis and NF-kappa B protein expression of the intestinal mucosa of rats with severe acute pancreatitis or obstructive jaundice. Hepatobiliar Pancreat Dis Intern 9: 537-546.

5. Büchler MW, Gloor B, Müller CA, Friess H, Seiler CA, Uhl W. Acute necrotizing pancreatitis: treatment strategy according to the status of infection. Ann Surg 2000; 232: 619-626.

6. Watanabe O, Baccino FM, Steer ML, Meldolesi J. Supramaximal caerulein stimulation and ultrastructure of rat pancreatic acinar cell: early morphological changes during development of experimental pancreatitis. Am J Physiol 1984; 246: G457-G467.

7. Houghton PJ, Zarka R, de las Heras B, Hoult JR. Fixed oil of Nigella sativa and derived thymoquinone inhibit eicosanoid generation in leukocytes and membrane lipid peroxidation. Planta Med 1995; 61 (1): 33-36.

8. Shabana A, El-Menyar A, Asim M, Al-Azzeh H, Al-Thani H. Cardiovascular benefits of black cumin (Nigella sativa). Cardiovasc Toxicol 2013; 13 (1): 9-21.

9. Woo CC, Kumar AP, Sethi G, Tan KH. Thymoquinone: potential cure for inflammatory disorders and cancer. Biochem Pharmacol 2012; 83 (4): 443-451.

10. Ashraf SS, Rao MV, Kaneez FS, Qadri S, Al-Marzouqi AH, Chandranath IS, Adem A. Nigella sativa extract as a potent antioxidant for petrochemical-induced oxidative stress. J Chromatogr Sci 2011; 49: 321-326.

11. Erel O. A novel automated method to measure total antioxidant response against potent free radical reactions. Clin Biochem 2004; 37 (2): 112-119.

12. Erel O. A new automated colorimetric method for measuring total oxidant status. Clin Biochem 2005; 38 (12): 1103-1111.

13. Bolukbas C, Bolukbas FF, Horoz M, Aslan M, Celik H, Erel O. Increased oxidative stress associated with the severity of the liver disease in various forms of hepatitis B virus infection. BMC Infect Dis 2005; 5: 95.

14. Woo CC, Kumar AP, Sethi G, Tan KH. Thymoquinone: potential cure for inflammatory disorders and cancer. Biochem Pharmacol 2012; 83 (4): 443-451.
15. Vaillancourt F, Silva $P$, Shi Q, Fahmi H, Fernandes JC, Benderdour M. Elucidation of molecular mechanisms underlying the protective effects of thymoquinone against rheumatoid arthritis. J Cell Biochem 2011; 112: 107-117.

16. Ragheb A, Elbarbry F, Prasad K, Mohamed A, Ahmed MS, Shoker A. Attenuation of the development of hypercholesterolemic atherosclerosis by thymoquinone Int J Angiol 2008; 17 (4): 186-192.

17. Gali-Muhtasib H, Roessner A, Schneider-Stock R. Thymoquinone: A promising anti-cancer drug from natural sources. Int J Biochem Cell Biol 2006; 38: 1249-1253.

18. Khader M, Bresgen N, Eckl PM. In vitro toxicological properties of thymoquinone. Food Chem Toxicol 2009; 47: 129-133.

19. Tsuji N, Watanabe N, Okamoto T, Niitsu Y. Specific interaction of pancreatic elastase and leucocytes to produce oxygen radicals and its implication in pancreatitis. Gut 1994; 35: 1659-1664.

20. Ding SP, Li JC, Jin C. A mouse model of severe acute pancreatitis induced with caerulein and lipopolysaccharide. World J Gastroenterol 2003; 9: 584--589.

21. Chan YC, Leung PS. Acute pancreatitis: animal models and recent advances in basic research. Pancreas 2007; 34 (1): 1-14.

22. Saluja AK, Bhagat L, Lee HS, Bhatia M, Frossard JL, Steer ML. Secretagogue-induced digestive enzyme activation and cell injury in rat pancreatic acini. Am J Physiol 1999; 276: G835-G842.

23. Mews P, Phillips P, Fahmy R, Korsten M, Pirola R, Wilson J et al. Pancreatic stellate cells respond to inflammatory cytokines: potential role in chronic pancreatitis. Gut 2002; 50: 535-541.

24. Yu JH, Kim H. Role of janus kinase/signal transducers and activators of transcription in the pathogenesis of pancreatitis and pancreatic cancer. Gut Liver 2012; 6: 417-422.

25. Bae GS, Kim MS, Jeong J, Lee HY, Park KC, Koo BS, Kim BJ, Kim TH, Lee SH, Hwang SY, Shin YK, Song HJ, Park SJ. Piperine ameliorates the severity of cerulein-induced acute pancreatitis by inhibiting the activation of mitogen activated protein kinases. Biochem Biophys Res Comm 410: 382-388.

26. Zhang XP, Zhang L, Chen LJ, Cheng QH, Wang JM, Cai W, Shen HP, Cai J. Influence of dexamethasone on inflammatory mediators and NFkappaB expression in multiple organs of rats with severe acute pancreatitis. World J Gastroenterol 13: 548-556.

27. Arslan SO, Gelir E, Armutcu F, Coskun O, Gurel A, Sayan H, Celik IL. The Protective Effect of Thymoquinone on Ethanol-induced Acute Gastric Damage in the Rat. Nutr Res 2005; 25: 673-680.

28. El Gazzar M, EI Mezayen R, Marecki JC, Nicolls MR, Canastar A, Dreskin SC. Anti-inflammatory effect of thymoquinone in a mouse model of allergic lung inflammation. Int Immunopharmacol 2006; 6: 1135-1142.

29. Tekeoglu I, Dogan A, Demiralp L. Effects of thymoquinone (volatile oil of black cumin) on rheumatoid arthritis in rat models. Phytother Res 2006; 20: 869-871.

30. Esrefoğlu M, Gul M, Ates B, Kadir Batcioglu K, Selimoglu MA. Antioxidative effect of melatonin, ascorbic acid and $\mathrm{N}$-acetylcysteine on caerulein-induced pancreatitis and associated liver injury in rats. World J Gastroenterol 2006; 12 (2): 259-264.

31. Alenzi FQ, El-Bolkiny Yel S, Salem ML. Protective effects of Nigella sativa oil and thymoquinone against toxicity induced by the anticancer drug cyclophosphamide. Br J Biomed Sci 2010; 67: 20-28.

Received June 15, 2016. Accepted July 8, 2016. 